19,3090980

UCRL-ID-106036

\title{
Examination of Yield Determination by the Magnetic Bubble Effect
}

R. M. Bevensee

DO MOT MirroflLM

COVER

October 5, 1990

This is an informal report intended primarily for internal or limited external distribution. The opinions and conclusions stated are those of the author and may or may not be those of the Laboratory.

Work performed under the auspices of the U.S. Department of Energy by the Lawrence Livermore National Laboratory under Contract W-7405-Eng-48. 
This document was prepared as an account of work sponsored by an agency of the United States Government. Neither the United States Government nor the University of California nor any of their employees, makes any warranty, express or implied, or assumes any legal liability or responsibility for the accuracy, completeness, or usefulness of any information, apparatus, product, or process disclosed, or represents that its use would not infringe privately owned rights. Reference herein to any specific commercial products, process, or service by trade name, trademark, manufacturer, or otherwise, does not necessarily constitute or imply its endorsement, recommendation, or favoring by the United States Government or the University of California. The views and opinions of authors expressed herein do not necessarily state or reflect those of the United States Government or the University of California, and shall not be used for advertising or product endorsement purposes.

\author{
This report has been reproduced \\ directly from the best available copy. \\ Available to DOE and DOE contractors from the \\ Office of Scientific and Technical Information \\ P.O. Box 62, Oak Ridge, TN 37831 \\ Prices available from (615) 576-8401, FTS 626-8401. \\ Available to the public from the \\ National Technical Information Service \\ U.S. Department of Commerce \\ 5285 Port Royal Rd. \\ Springfield, VA 22161
}

Price

Code

A01

Papercopy Prices

A02

A03

A04

A05

A06

A07

A08

A09

A10

A11

A12

A13

A14

A15

A16

A17

A18

A19

A20

A21

A22

A23

A24

A25

A99
Page

Range

Microfiche 


\section{DISCLAIMER}

This report was prepared as an account of work sponsored by an agency of the United States Government. Neither the United States Government nor any agency Thereof, nor any of their employees, makes any warranty, express or implied, or assumes any legal liability or responsibility for the accuracy, completeness, or usefulness of any information, apparatus, product, or process disclosed, or represents that its use would not infringe privately owned rights. Reference herein to any specific commercial product, process, or service by trade name, trademark, manufacturer, or otherwise does not necessarily constitute or imply its endorsement, recommendation, or favoring by the United States Government or any agency thereof. The views and opinions of authors expressed herein do not necessarily state or reflect those of the United States Government or any agency thereof. 


\section{DISCLAIMER}

Portions of this document may be illegible in electronic image products. Images are produced from the best available original document. 


\title{
Examination of Yield Determination by the Magnetic Bubble Effect
}

\author{
R. M. Bevensee
}

UCRL-ID--106036

DE91 002997

\author{
Lawrence Livermore National Laboratory \\ University of California \\ P. O. Box 808, Mail Code L-156 \\ Livermore, CA 94550, (415) 422-6787
}

\section{Overview}

This report surveys the preliminary work of P. J. Ebert, a proponent of the "Magnetic Bubble" Effect, as well as conclusions reached by L. F. Wouters and others. The idea behind the Magnetic Bubble Effect is that an exploding fireball from a surface or subsurface nuclear explosion releases electrons which circulate around the earth's magnetic field lines and create an expanding magnetic dipole which persists underground for $\simeq 0.01 \mathrm{sec}$. This dipole radiates a low-frequency electromagnetic field through the earth in a diffusive manner because the earth's conduction current overwhelms the displacement current at VLF and ELF frequencies. By using this concept of diffusive fields it might be possible to estimate the yield of an underground nuclear test from transient low-frequency field measurements on or near the ground in the range $1-5 \mathrm{~km}$ from ground zero.

We closely examine the diffusive-field description of the transient fields by L. W. Miller (1973). Miller's work enables us to derive rather easily the "Green-function" fields in space and 
time of a spatially and temporally impulsive vertical magnetic dipole, $\mathrm{m}_{\mathrm{z}}$, and horizontal dipole, $\mathrm{m}_{\mathrm{x}}$, in a homogeneous earth of scalar electrical conductivity $\sigma$, magnetic permeability $\mu_{\mathrm{o}}$, and relative dielectric constant, $\varepsilon_{\mathrm{r}}$, and account for the earth-air interface. The fields of an event would be the convolution of these Green-function fields and the temporally evolving $m_{x}-$ and $m_{z}$-dipoles integrated over space. The spectra of the Green-function fields are readily calculated, and multiplied by the magnetic-dipole spectrum to give the event-field spectra.

From Miller's formulas we estimate the quantitative fields to be expected in situations discussed by Ebert and Wouters. Then we estimate the early peak fields measured in several events reported by Zablocki, who, in the writer's opinion, made a qualitatively incorrect analysis. We comment on the rather brief report of Malik, Fitzhugh, and Homuth, who dismiss the Magnetic Bubble source in favor of the electroseismic effect based on analysis of one event. Our estimate of $\left(\mathrm{E}_{\phi}\right)_{\max }$ indicates that the Magnetic Bubble would account for features seen in the field data. We next review measurements of ELF fields from underground events at NTS by Sweeney (1989). Comparison between magnitude estimates and measurements on three events is inconclusive, but does not rule out the Magnetic Bubble as the primary field source.

A review of data summarized by Wouters (1980) indicates that estimates of fields differed in four measurements by factors of $10-100$. Perhaps the inclusion of ground surface reflections would improve these estimates.

The conclusions from this study are as follows. We have compared measured early-time peak surface fields in various underground nuclear events with predictions from Miller's infiniteearth field expressions using Wouter's expression for the maximum magnetic dipole moment (with $W^{3 / 4}$ changed to $W$, yield) and its temporal history. Those comparisons sometimes differ within an order of magnitude, and sometimes by more, of measurements reported by Zablocki, Sweeney, and Malik et. al., for reasons not fully understood. Miller's expressions allow us to correct for the earth-air interface; use of these more accurate field formulas might result in better agreement with 
measurements. Past instrumentation has sometimes lacked the required bandwidth, which can be estimated from the event-dipole time history and the spectra of Miller's Green-function fields.

The recommendations from this study are as follows. For an advanced concept project we propose field experiments, coupled with modeling, to (a) confirm the diffusion theory,

(b) optimize and calibrate the measurement systems, and (c) understand better the nature of the EM source fields of an underground event. As an initial study to achieve goals (a) and (b) we propose to carry out a series of experiments at NTS with a downhole controlled source to simulate the magnetic-dipole source of an underground explosion. We will use surface sensors to measure the fields produced by the downhole source. Depending on the design criteria, we might also be able to create a downhole or surface-horizontal electric dipole source and study its fields with suitably modified diffusive-field theory. This will allow us to develop ways to better decouple the effects of multiple sources.

The diffusion theory will be used to design the experiment and resolve such details as the necessary distances and orientation of the sensors and required bandpass of the measurement system. We will locate the magnetic dipole source at a depth of a few tens of meters in a borehole which has been logged so that the medium characteristics are well known. In this way we can see if the measurements made in the NTS EM environment confirm the theoretical predictions.

Once we have completed the initial calibration and field testing of the EM measurement system, we will be ready to field the system during underground tests. Sensors will be deployed at distances less than $5 \mathrm{~km}$ from GZ, and will be designed to decouple optimally the fields created by magnetic or electric dipoles. The data will then be used to predict yield from EM measurements. Based on the results of one or two tests, provided that the data collection is successful, we will be in a position to recommend whether the technique is successful enough to warrant further study as an alternative system for yield measurement.

The personnel and funding requirements are stated at the end of this report. 


\section{Work of P. J. Ebert}

In 1989 Ebert strongly advocated the "Magnetic Bubble" effect as a means of non-intrusive verification of underground nuclear yield [1]. We summarize his salient results (in rationalized MKS units) below.

Following Raizer's theoretical approach [2],

$r_{c}($ meter $)=17 W_{k \text { Ton }}^{1 / 3}, r_{c}=$ final cavity radius; $W$, yield

$\mathrm{V}_{c}\left(\mathrm{~meter}^{3}\right)=\frac{4}{3} \pi \mathrm{r}_{\mathrm{c}}^{3}=2.06 \times 10^{4} \mathrm{~W}, \quad \mathrm{~V}_{\mathrm{c}}=$ cavity volume

$E_{m}($ Joule $)=\left(B_{d}^{2} / 2 \mu\right) V_{c}, \quad E_{m}=$ energy magnetic in the cavity

$$
\begin{aligned}
& B_{o}=\text { earth's field }=0.5 \times 10^{-4} \frac{\mathrm{web}}{\mathrm{m}^{2}} \\
& \mu=4 \pi \times 10^{-7}
\end{aligned}
$$

The Bubble is produced in $\Delta t \simeq 0.01 \mathrm{sec}$ (CORRTEX measurements).

$\mathrm{M}$, magnetic dipole moment $=\frac{2 \pi \mathrm{B}_{\mathrm{o}}}{\mu} \mathrm{r}_{\mathrm{c}}^{3}$ Amp $\mathrm{m}^{2}$

(Found by substituting $B_{o} / \mu=H_{o}=I_{o} / 2 r_{c}, I_{o}$ (Amp) being the ring current circling the fireball, into $M=I_{0} \pi r_{c}^{2}$ )

Then $\Delta B$, change in $B$ a distance $R$ away is

$$
\Delta B=B_{o} r_{c}^{3} e^{-k R} \sin \beta / 2 R^{3} \quad\left(\frac{\mu M}{2 \pi}=B_{o} r_{c}^{3}\right)
$$




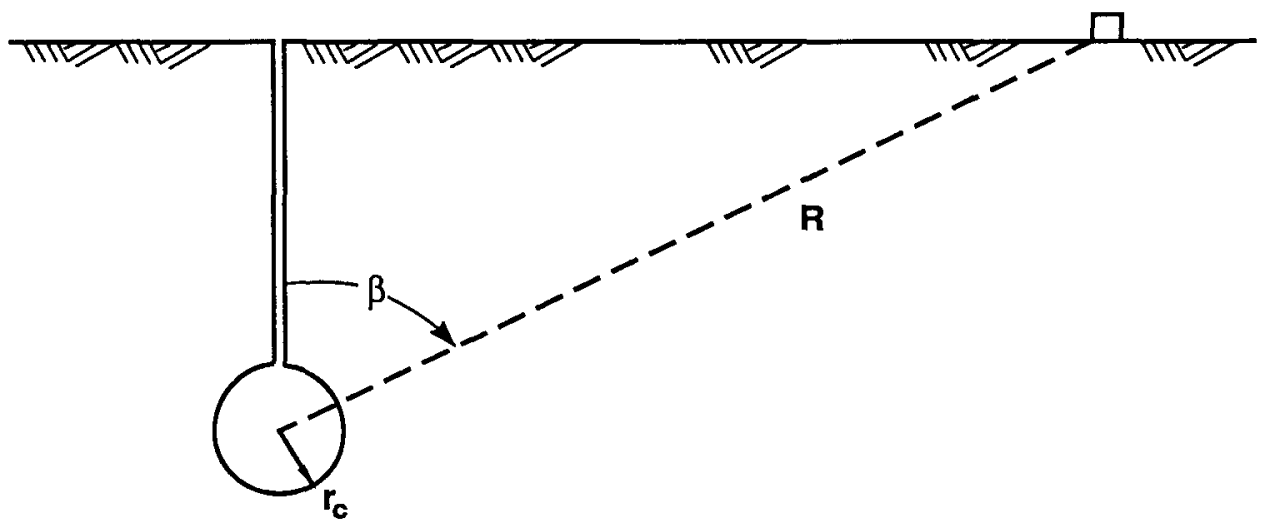

where $\mathrm{k}$, attenuation $=\sqrt{\omega \mu \sigma / 2}$,

in which $\sigma$, earth conductivity in $\mathrm{mho} / \mathrm{m}$, and $\omega$ is the primary event frequency, assumed by Ebert to be $(2 \pi / \Delta t)$..

Then the peak EMF (volt) induced in a coil at $R$ is estimated as

$\mathrm{EMF}($ volt $) \simeq \mathrm{AN}(\Delta \mathrm{B} / \Delta \mathrm{t})$

where $A=$ coil area $\left(\mathrm{m}^{2}\right), N=$ number of turns.

For the following data: $W=1 \mathrm{kTon}, \mathrm{r}_{\mathrm{c}}=17 \mathrm{~m}, \mathrm{E}_{\mathrm{m}}=20 \mathrm{~J}, \Delta \mathrm{t}=0.01 \mathrm{~s}, \mathrm{k}=0.004 \mathrm{~m}^{-1}$ (NTS), $\sin \beta=0.8, R=500 \mathrm{~m}, A=10^{2} \mathrm{~m}^{2}, \mathrm{~N}=10^{2}$ we obtain

$$
\mathrm{EMF}=1.1 \times 10^{-4} \text { volt }
$$

(This agrees closely with an estimate from Wouter's work to follow,

$$
\left.E M F \cong N A \dot{B}=N A \mu_{0} \omega_{o} H_{o} r_{c}^{3} \frac{e^{-\beta 1}}{1^{3}} \sqrt{\cos ^{2} \psi+\sin ^{2} \psi / 4} \simeq 1.4 \times 10^{-4}\right)
$$

Ebert deduces from an error analysis that the principal errors are in attenuation $\mathrm{k}$ and in a factor $\mathrm{K}$ defined by $\mathrm{r}_{\mathrm{c}}^{3}=\mathrm{KW}\left(\mathrm{K}\right.$ is $17^{3}$ in (1)). 
The advantages claimed by Ebert for this method of yield measurement are: (1) nonintrusive, (2) VLF frequencies predominate in the range $3-30 \mathrm{kHz}$, requiring no high frequency If instrumentation, (3) no access to emplacement hole is required, (4) no zero-time signal is needed, (5) a nearby satellite hole is unnecessary, (6) it is less costly than hydrodynamic-yield (H$\mathrm{Y}$ ) techniques, (7) it is potentially more accurate than $\mathrm{H}-\mathrm{Y}$ techniques, [one reason being it measures $\left.\mathrm{W}_{\text {not }} \mathrm{W}^{1 / 3}\right]$, (8) one can detect seismic decoupling, (9) it is insensitive to small anisotropies/inhomogeneities, (10) it is insensitive to test instrumentation downhole because of its small mass relative to the earth mass displaced, and (11) there is a potential for measuring yields down to $1 \mathrm{kTon}$.

The disadvantages, according to Ebert, are: (1) high- $\sigma$ attenuates the signals more strongly, (2) high- $\mu$ volumes would upset measurements, (3) the rapid decrease of cavity $\sigma$ toward the end of the fireball, (4) unusual propagation paths would upset the $\mathrm{R}^{-3}$ dependence of the pickup-coil EMF.

Ebert says that $\sim 4 \mathrm{kHz}$ magnetic dipole transmission was successfully demonstrated at NTS in 1966 but that neither this demonstration nor a later one of Malik, et-al [3] contains data amenable to quantitative interpretation. We shall see that the magnetic dipole frequency spectrum is considerably lower than $4 \mathrm{kHz}$.

To conclude this summary of the earliest features of Ebert's work in 1989 we quote a table of EMF $(\mu \mathrm{V})$ vs W (kTon) following the analysis of (1) - (9) except that $\mathrm{R}$ is chosen to be $244 \mathrm{~W}^{1 / 3} \mathrm{~m}$ for $\beta=60^{\circ}, \Delta \mathrm{t}=0.6 \times 10^{-3} \mathrm{~W}^{1 / 3}$ and $\mathrm{r}_{\mathrm{c}}=4.93 \mathrm{~W}^{1 / 3}$ (both from a formalism developed by Moss [4] for determining hydrodynamic yield from particle velocity together with the empirical strong shock relation $r_{d} / W^{1 / 3}=6.29 \times\left(\Delta t_{m s e d} / W^{1 / 3}\right)^{0.475}$, valid up to a scaled time $\Delta t=$ $0.6 \times 10^{-3} \mathrm{~W}^{1 / 3} \mathrm{~s}$, assumed by Ebert to be the Bubble lifetime) and $\mathrm{k}$ of (7) obtained with $\omega=2 \pi \mathrm{f}_{\mathrm{c}}$ $=2 \pi / \Delta \mathrm{t}$. Eqs. (6) and $\left(10^{\prime}\right)$ then give $\mathrm{EMF}=\mathrm{ANB}=3 . \times 10^{-7} \mathrm{AN} \mathrm{e}^{-\mathrm{kR}} \mathrm{W}^{1 / 3}, \mathrm{kR}=2.0 \mathrm{~W}^{1 / 6}$. 
For $\mathrm{AN}=10^{4} \mathrm{~m}^{2}$ Ebert obtains

\begin{tabular}{|c|c|c|c|}
\hline $\mathrm{W}(\mathrm{KT}$ Ton) & $\mathrm{R}(\mathrm{m})$ & $\mathrm{EMF}(\mu \mathrm{V})$ & Bevensee (check) \\
\hline \hline 8 & 488. & 92. & 88. \\
\hline 27 & 732. & 32. & (not computed) \\
\hline 64 & 976. & 14. & (not computed) \\
\hline 125 & 1220. & 7. & 6.8 \\
\hline
\end{tabular}

The $\Delta \mathrm{t}$ Bubble lifetime just assumed is considerably shorter than Wouter's value.

\section{Work of L. F. Wouters}

In 1989 Wouters examined four representative models of the underground electromagnetic pulse (EMP) from a fireball, including the diamagnetic plasma ("Magnetic Bubble") [5]. We now summarize his computations of the $\dot{B}\left(\right.$ weber $\left./\left(\mathrm{m}^{2} \mathrm{sec}\right)\right)$ - field generated by the "Bubble".

Wouters assumes a somewhat different dependence of final cavity radius $r_{c}$ relative to yield W, namely

$$
r_{c}=R_{o}\left(\rho d_{o}\right)^{-1 / 4}\left[W(k T o n) \times 10^{3}\right]^{1 / 4} \approx 32 \text { meter }
$$

where $R_{o}=70 \mathrm{~m}, \rho$, earth density $=1.8 \mathrm{~g} / \mathrm{cm}^{3}=1.8 \times 10^{3} \mathrm{~kg} / \mathrm{m}^{3}, d_{o}=125 \mathrm{~m}$, relative to the MERLIN data $(\mathrm{W}=10$. $\mathrm{kTon})$.

The maximum magnetic dipole moment $M$ from (5) is 


$$
\begin{aligned}
\mathrm{M} & \simeq 2 \pi \frac{\mathrm{B}_{\mathrm{o}}}{\mu} \mathrm{r}_{\mathrm{c}}^{3}=2 \pi \frac{\mathrm{B}_{\mathrm{o}}}{\mu}\left[\mathrm{R}_{\mathrm{o}}\left(\rho \mathrm{d}_{\mathrm{o}}\right)^{-1 / 4}\right]^{3} \mathrm{~W}(\mathrm{kTon})^{1 / 4} \times 10^{3 / 4} \\
& \simeq 1.48 \times 10^{6} \mathrm{~W}(\mathrm{kTon})^{3 / 4}
\end{aligned}
$$

which checks closely his Fig. 4-4 for M vs W(kTon). He takes

$$
\Delta \mathrm{H}_{\text {peak }}=h_{\mathrm{s}} \sqrt{\cos ^{2} \psi+\sin ^{2} \psi / 4}, h_{\mathrm{s}}=\mathrm{H}_{\mathrm{o}} \mathrm{r}_{\mathrm{c}}^{3} \mathrm{e}^{-\beta l} \mathrm{~h}^{3}
$$

where $\psi$ is the (azimuthal) angle relative to the earth's $\overline{\mathrm{H}}_{\mathrm{o}}$-vector, $\beta=\sqrt{\omega \mu \sigma / 2} \mathrm{~m}^{-1}$, and 1 , meter, is the slant distance to the detector. Eq. (13) is essentially (6) without a factor 2 in the denominator.

Then $\dot{B}=d B / d t$ at the detector (receiver coil is taken

$$
\dot{\mathrm{B}}=\mu_{\mathrm{o}} \omega_{\mathrm{o}} \Delta \mathrm{H},
$$

where $\omega_{0}=2 \pi(10 \mathrm{~Hz}) \simeq 63$ is the frequency of a half sinusoid

fitted to the cavity growth-collapse history.

Combining (11) and (13),

$$
\dot{\mathrm{B}}\left(\frac{w e b}{\mathrm{~m}^{2} \mathrm{sec}}\right)=\mu_{\mathrm{o}} \omega_{\mathrm{o}} \mathrm{H}_{\mathrm{o}} \mathrm{r}_{\mathrm{c}}^{3}\left(\mathrm{e}^{-\beta 1} /^{3}\right) \sqrt{\cos ^{2} \psi+\sin ^{2} \psi / 4}
$$

we find for $r_{c}=32 \mathrm{~m} .1=282 \mathrm{~m}, \mathrm{e}^{-\beta 1}=0.9, \sqrt{\cos ^{2} \psi \ldots} \simeq 0.8$,

$$
\dot{\mathrm{B}} \simeq 3.3 \mu \mathrm{V} / \mathrm{m}^{2},\left(\mathrm{~B} \cong \frac{\dot{\mathrm{B}}}{\omega_{\mathrm{o}}}=52 \mathrm{nT}\right)
$$

which is close to the mean value in Wouter's Table 4.2.

Eq. (17) represents a large value of field, for the (peak) EMF induced in a coil of NA $=10^{4}$ would be 33 . $\mathrm{mVolt}$. It is larger because the slant distance 1 to the receiver is only $282 \mathrm{~m}$. If 1 


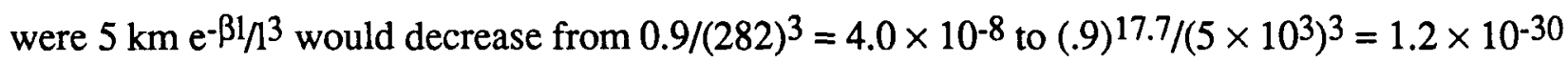
(!). We shall see that this gives far too pessimistic a value for $\dot{\mathrm{B}}$.

\section{Work of L. W. Miller}

In 1973 Miller in a brilliant report [6] analyzed the radiation from a point magnetic dipole impulsive in time through an earth of high electrical conductivity and obtained expressions for the diffusive fields in space-time. He also showed how to treat reflection and transmission at the earth's surface, which depends on the orientation of both the earth's magnetic field and the source dipole. Below we will convert his equations to rationalized MKS form, apply them to the vertical component of the Magnetic Bubble dipole, neglect reflection from the earth's surface, and predict the magnitude of the EMF in a pickup coil $1-5 \mathrm{~km}$ from the fireball.

\subsection{Equations}

Miller starts with Maxwell's equations in CGS units for a medium of uniform conductivity $\sigma$ and relative dielectric constant $\varepsilon_{\mathrm{r}}($ his $\varepsilon$ ),

$$
\begin{aligned}
& \nabla \times \overline{\mathrm{E}}(\overline{\mathrm{r}}, \mathrm{t})+\frac{1}{\mathrm{c}} \dot{\overline{\mathrm{B}}}(\mathrm{r}, \mathrm{t})=0, \quad \nabla \cdot \overline{\mathrm{B}}=0 \\
& \nabla \times \overline{\mathrm{B}}-\frac{\varepsilon_{\mathrm{r}}}{\mathrm{c}} \dot{\overline{\mathrm{E}}}=\frac{4 \pi}{\mathrm{c}}\left(\sigma \mathrm{E}+\overline{\mathrm{J}}_{\mathrm{o}}(\overline{\mathrm{r}}, \mathrm{t})\right), \quad \nabla \cdot \overline{\mathrm{E}}=4 \pi \rho(\overline{\mathrm{r}}, \mathrm{t})
\end{aligned}
$$

Here $\mathrm{c}=$ light velocity in vacuo, $3 \times 10^{10} \mathrm{~cm} / \mathrm{s}$, and charge density $\rho$ is defined by the second of (19).

Since $\overline{\mathrm{J}}_{\mathrm{o}}$ of the fireball is assumed to be solenoidal $\left(\nabla \cdot \overline{\mathrm{J}}_{\mathrm{o}}=0\right)$ it is written as

$$
\overline{\mathrm{J}}_{\mathrm{o}}=\mathrm{c} \nabla \times \overline{\mathrm{M}}(\overline{\mathrm{r}}, \mathrm{t}), \quad \overline{\mathrm{M}}=\overline{\mathrm{m}} \delta(\overline{\mathrm{r}}) \delta(\mathrm{t})
$$

which introduces magnetic dipole moment $\overline{\mathrm{M}}$ as a spatial-temporal impulse.

$$
\text { Writing } \bar{B}=\overline{\mathrm{H}}+4 \pi \overline{\mathrm{M}}
$$


we obtain Maxwell's equations [6, (18) - (19)] in the forms

$$
\begin{aligned}
& \nabla \times \overline{\mathrm{E}}+\frac{1}{\mathrm{c}} \dot{\mathrm{H}}=-\frac{4 \pi}{\mathrm{c}} \dot{\mathrm{M}} \\
& \nabla \times \dot{\overline{\mathrm{H}}}-\frac{\varepsilon_{\mathrm{I}}}{\mathrm{c}} \dot{\mathrm{E}}-\frac{4 \pi \sigma}{\mathrm{c}} \overline{\mathrm{E}}=0
\end{aligned}
$$

These are solved within an infinite medium via a Hertz vector $\bar{\Pi}(\bar{r}, \mathrm{t}) . \bar{\Pi}$ must be integrated over circular frequency $\omega$, where each $\omega$-component propagates as $\mathrm{e}^{\mathrm{i} \Gamma \mathrm{r}}, \Gamma$ complex $\left(\mathrm{e}^{-\mathrm{i} \omega t}\right.$ time dependence). Because $\omega \varepsilon_{\mathrm{T}} \ll 4 \pi \sigma$ (CGS units) at all frequencies of interest, which implies negligible displacement current compared to conduction current, the evaluation of $\bar{\Pi}(\overline{\mathrm{r}}, \mathrm{t})$ by integration in the complex $-\omega$ plane simplifies at all points $r$ such that

$$
\mathrm{r} \gg \mathrm{q} \text { defined as } \frac{c}{4 \pi \sigma}(\mathrm{CGS}) \quad \text { or } \mathrm{r} \gg \frac{\sqrt{\varepsilon_{\mathrm{r}} / \mu}}{\sigma}(\mathrm{MKS}) \text {. }
$$

Note that for $\sigma=10^{-2} \mathrm{mho} / \mathrm{m}$ or $9 \times 10^{7} \mathrm{sec}^{-1}$ CGS q is only $26 \mathrm{~cm}$.; even for $\sigma=10^{-4} \mathrm{q}$ is only $26 \mathrm{~m}$.

Miller's final expression for the diffusive fields in CGS units in spherical coordinates, due to $\overline{\mathrm{m}}=\overline{\mathrm{a}}_{\mathrm{z}} \mathrm{m}_{\mathrm{z}} \delta(\mathrm{t})$, at all $\mathrm{r}$ satisfying $(24)$ are (note $\overline{\mathrm{m}}=\int \overline{\mathrm{M}} \mathrm{dV}$ )

$$
\begin{aligned}
& h_{\mathrm{T}}(r, \theta, t)=\frac{16 \mathrm{~m}_{\mathrm{z}} q c}{\sqrt{\pi}} \frac{\exp \left(-\mathrm{r}^{2} / 4 \mathrm{qct}\right)}{(4 \mathrm{qct})^{5 / 2}} \cos \theta \\
& \mathrm{h}_{\theta}(\mathrm{r}, \theta, \mathrm{t})=-\frac{16 \mathrm{~m}_{\mathrm{z}} \mathrm{qc}}{\sqrt{\pi}}\left(1-\frac{\mathrm{r}^{2}}{4 \mathrm{qct}}\right) \frac{\exp \left(-\mathrm{r}^{2} / 4 \mathrm{qct}\right)}{(4 \mathrm{qct})^{5 / 2}} \sin \theta \\
& \mathrm{e}_{\phi}(\mathrm{r}, \theta, \mathrm{t})=\frac{80 \mathrm{~m}_{\mathrm{z}} \mathrm{q}^{2} \mathrm{c}}{\sqrt{\pi}}\left(1-\frac{2}{5} \frac{\mathrm{r}^{2}}{4 \mathrm{qct}}\right) \frac{\mathrm{r} \exp \left(-\mathrm{r}^{2} / 4 \mathrm{qct}\right)}{(4 q c t)^{7 / 2}} \sin \theta
\end{aligned}
$$


These satisfy (22), (23). We have replaced Miller's capital letters by small letters e and $\mathrm{h}$ to denote Green-function fields from an impulsive $\delta(t)$ - source. The fields are conveniently written in terms of a characteristic time $t_{r}$ which depends on $r$,

$$
t_{r}=r^{2} / 4 q c
$$

In terms of a normalized time $\mathrm{T}=\mathrm{t} / \mathrm{t}_{\mathrm{r}}(25)-(27)$ are

$$
\begin{aligned}
& h_{\mathrm{r}}(r, \theta, T)=\frac{16 \mathrm{~m}_{\mathrm{z}} q c}{\sqrt{\pi} \mathrm{r}^{5}}\left[\mathrm{~T}^{-5 / 2} \mathrm{e}^{-1 / T}\right] \cos \theta \\
& \mathrm{h}_{\theta}(\mathrm{r}, \theta, T)=\frac{16 \mathrm{~m}_{\mathrm{z}} \mathrm{qc}}{\sqrt{\pi} \mathrm{r}^{5}}\left[\left(1-\frac{1}{\mathrm{~T}}\right) \mathrm{T}^{-5 / 2} \mathrm{e}^{-1 / T}\right] \sin \theta \\
& \mathrm{e}_{\phi}(\mathrm{r}, \theta, T)=\frac{80 \mathrm{~m}_{\mathrm{z}} \mathrm{qc}}{\sqrt{\pi} \mathrm{r}^{6}}\left[\left(1-\frac{2}{5} \frac{1}{\mathrm{~T}}\right) \mathrm{T}^{-7 / 2} \mathrm{e}^{-1 / T}\right] \sin \theta
\end{aligned}
$$

Miller has plots [6] of the behaviors of these bracketed quantities; each one reaches a peak value of nearly 1 or \pm 2 in about $T=t / t_{r} \simeq 1 / 3$ or $1 / 4$. Note that the fields decay as $r^{-5}$ or $r^{-6}$ !

We now want to convert (25) - (31) to (rationalized) MKS form. One straightforward way to do this is to rearrange the terms of the starting Eq. (18) - (23) so they are in MKS form. If certain groupings of CGS terms look like MKS terms in these equations of $M K S$ form it follows that the same groupings can be replaced by their MKS terms in the answers. This is a way to convert CGS functions to MKS functions, independent of the numerical relations between CGS and MKS quantities.

The CGS groupings and MKS correspondences are 


$$
\begin{aligned}
& \mathrm{E}_{\mathrm{MKS}}=\sqrt{\mu_{\mathrm{o}} / \varepsilon_{\mathrm{o}}} \mathrm{E}_{\mathrm{CGS}}, \quad \mathrm{H}_{\mathrm{MKS}}=\mathrm{H}_{\mathrm{CGS}}, \quad \mu_{\mathrm{o}} \varepsilon_{\mathrm{o}} \text { are MKS, } \varepsilon_{\mathrm{T}} \text { remains } \varepsilon_{\mathrm{T}} \\
& \sigma_{\mathrm{MKS}}=\varepsilon_{\mathrm{o}} 4 \pi \sigma_{\mathrm{CGS}}, \quad \mathrm{B}_{\mathrm{MKS}}=\mu_{\mathrm{o}} \mathrm{B}_{\mathrm{CGS}} \\
& \mathrm{J}_{\mathrm{MKS}}=\frac{4 \pi}{\mathrm{c}} \mathrm{J}_{\mathrm{CGS}}, \quad \mathrm{M}_{\mathrm{MKS}}=4 \pi \mathrm{M}_{\mathrm{CGS}}, \mathrm{c}=\frac{1}{\sqrt{\mu_{\mathrm{o}} \varepsilon_{\mathrm{o}}}}=3 \times 10^{8} \frac{\mathrm{m}}{\mathrm{s}}
\end{aligned}
$$

$\overline{\mathrm{M}}$ was defined relative to $\overline{\mathrm{J}}_{\mathrm{o}}$ in (20). The relation $\overline{\mathrm{J}}_{\mathrm{o}}=c \nabla \times \overline{\mathrm{M}}$ in CGS and $\overline{\mathrm{J}}_{\mathrm{o}}=\nabla \times \overline{\mathrm{M}}$ amp/m in MKS imply the conversion factor for $\mathrm{m}=\int \mathrm{Mdv}$ of

$$
\left(\frac{1 \mathrm{~m}_{\mathrm{MKS}}}{10^{3} \mathrm{~m}_{\mathrm{CGS}}}\right)
$$

i.e. $10^{3} \mathrm{~m}_{\mathrm{CGS}}$ units $=1 \mathrm{~m}_{\mathrm{MKS}}$ unit.

Now the conditions (24) for applicability of the diffusive-field expressions becomes

$$
\mathrm{r} \gg \mathrm{q}_{\mathrm{MKS}}=\frac{c \varepsilon_{\mathrm{o}}}{\sigma_{\mathrm{MKS}}}=\frac{2.65 \times 10^{-3}}{\sigma_{\mathrm{MKS}}} \text { meter }
$$

The CGS fields of (25) - (27) converted to MKS units are

$$
\begin{aligned}
& h_{\mathrm{z}}(\mathrm{r}, \theta, \mathrm{t})=\frac{4 \mathrm{~m}_{\mathrm{z}}}{\pi \sqrt{\pi}} \frac{1}{\sigma \mu_{\mathrm{o}}} \frac{\exp \left(-\mathrm{r}^{2} \mu_{\mathrm{o}} \sigma / 4 \mathrm{t}\right)}{\left(4 \mathrm{t} / \mu_{\mathrm{o}} \sigma\right)^{5 / 2}} \cos \theta \quad\left(\frac{\mathrm{amp}}{\mathrm{m} \cdot \mathrm{sec}}\right) \\
& \mathrm{h}_{\theta}(\mathrm{r}, \theta, \mathrm{t})=-\frac{4 \mathrm{~m}_{\mathrm{z}}}{\pi \sqrt{\pi}\left(\sigma \mu_{\mathrm{o}}\right)}\left(1-\frac{\mathrm{r}^{2} \mu_{\mathrm{o}} \sigma}{4 \mathrm{t}}\right) \frac{\exp \left(-\mathrm{r}^{2} \mu_{\mathrm{o}} \sigma / 4 \mathrm{t}\right)}{\left(4 \mathrm{t} / \mu_{\mathrm{o}} \sigma\right)^{5 / 2}} \sin \theta \quad\left(\frac{\mathrm{amp}}{\mathrm{m} \cdot \mathrm{sec}}\right) \\
& \mathrm{e}_{\phi}(\mathrm{r}, \theta, \mathrm{t})=-\frac{20 \mathrm{~m}_{\mathrm{z}}}{\pi \sqrt{\pi}} \frac{1}{\left(\sigma \mu_{\mathrm{o}}\right)} \frac{1}{\sigma}\left(1-\frac{2}{5} \frac{\mathrm{r}^{2} \mu_{\mathrm{o}} \sigma}{4 \mathrm{t}}\right) \frac{\mathrm{rexp}\left(-\mathrm{r}^{2} \mu_{\mathrm{o}} \sigma / 4 \mathrm{t}\right)}{\left(4 \mathrm{t} / \mu_{\mathrm{o}} \sigma\right)^{7 / 2}} \sin \theta \quad\left(\frac{\text { volt }}{\mathrm{m} \cdot \mathrm{sec}}\right)
\end{aligned}
$$

with $\mathrm{m}_{\mathrm{z}}$ of units amp. $\mathrm{m}^{2}$. (The coefficients are checked following (79)). 


\subsection{The Event Fields as Convolutions of (34) - (36) and the Magnetic Dipole Time History}

The dimensions of (34) - (36) remind us that these are the fields of a per-unit-time source $m_{z}(t)$ at $t=0$. If $m_{z}(t)$ has a general time variation for $t \geq 0$ the fields are a convolution of $m_{z}(t)$ with (34) - (36). For example

$$
\mathrm{H}_{\theta}(\mathrm{r}, \theta, \mathrm{t})_{\mathrm{net}},\left(\frac{\mathrm{amp}}{\mathrm{m}}\right)=-\frac{4}{\pi \sqrt{\pi} \sigma \mu_{\mathrm{o}}} \sin \theta \int_{0}^{\mathrm{l}} \mathrm{m}_{\mathrm{z}}\left(\mathrm{t}-\mathrm{t}^{\prime}\right)\left(1-\frac{\mathrm{r}^{2} \mu_{\mathrm{o}} \sigma}{4 \mathrm{t}^{\prime}}\right) \frac{\exp \left(-\mathrm{r}^{2} \mu_{\mathrm{o}} \sigma / 4 \mathrm{t}^{\prime}\right)}{\left(\frac{4 \mathrm{t}^{\prime}}{\mu_{\mathrm{o}} \sigma}\right)^{5 / 2}} d \mathrm{t}^{\prime}
$$

In terms of the reference time $\left(t_{r}\right)_{M K S}=r^{2} \mu_{o} \sigma / 4$ and $T=t / t_{r},(37)$ is

$$
H_{\theta}(r, \theta, T)=-\frac{4 t_{\mathrm{r}}}{\pi \sqrt{\pi} \mu_{\mathrm{o}} \sigma} \frac{\sin \theta}{\mathrm{r}^{5}} \int_{0}^{\mathrm{T}} \mathrm{m}_{\mathrm{z}}\left(\mathrm{T}-\mathrm{T}^{\prime}\right)\left(1-\frac{1}{\mathrm{~T}^{\prime}}\right) \frac{\mathrm{e}^{-1 / \mathrm{T}^{\prime}}}{\left(\mathrm{T}^{\prime}\right)^{5 / 2}} d \mathrm{~T}^{\prime}\left(\frac{\mathrm{amp}}{\mathrm{m}}\right)
$$

For $r=1 \mathrm{~km}, \sigma=0.001$ (low) $\mathrm{t}_{\mathrm{r}}=0.3 \mathrm{~ms}$; the Bubble lasts many tens of millisec. [5]. $\mathrm{H}_{\theta}$ peaks at $T^{\prime} \simeq 1 / 3$. Hence, to good approximation we can approximate (38) by

$$
\mathrm{H}_{\theta}(\mathrm{r}, \theta, \mathrm{T}) \simeq-\frac{4 \mathrm{~L}_{\mathrm{L}}}{\pi \sqrt{\pi} \sigma \mu_{\mathrm{o}}} \frac{\sin \theta}{\mathrm{r}^{5}} \mathrm{~m}_{\mathrm{z}}\left(\mathrm{T}-\frac{1}{3}\right) \underbrace{\int_{0}^{\infty}\left(1-\frac{1}{\mathrm{~T}^{\prime}}\right) \frac{\mathrm{e}^{-1 / \mathrm{T}^{\prime}}}{\left(\mathrm{T}^{\prime}\right)^{5 / 2}} \mathrm{dT}}_{\simeq 0.7}
$$

and $\mathrm{B}_{\theta}=\mu_{\mathrm{o}} \mathrm{H}_{\theta}$ is nearly 


$$
\begin{aligned}
B_{\theta}(r, \theta, t) & \simeq-\frac{4(0.7) t_{r}}{\pi \sqrt{\pi} \sigma} \frac{1}{r^{5}} m_{z}\left(t-\frac{1}{3} t_{r}\right)=-\frac{2.8 \mu_{o}}{4 \pi \sqrt{\pi} r^{3}} m_{z}\left(\frac{w e b}{m^{2}}\right) \\
& \simeq-\frac{1.6 \times 10^{-7} m_{z}}{r^{3}} \quad(\sigma \text { has cancelled })
\end{aligned}
$$

$\sigma$ has cancelled only because $t_{T}=r^{2} \mu_{o} \sigma / 4<<$ duration of the Bubble.

Now if we use Wouter's expression (12) for $M_{\max }=\left(m_{\mathrm{z}}\right)_{\max }\left(\operatorname{amp~} \mathrm{m}^{2}\right)$ but change the $W^{3 / 4}$-dependence to a W-dependence according to Ebert's (5) and use (1) and take $\Delta t=30 \mathrm{msec}$ for the nearly-linear rise to the maximum we get

$$
\left(\mathrm{m}_{\mathrm{z}}\right)_{\max } \simeq 1.48 \times 10^{6} \mathrm{~W}(\mathrm{kTon}) \quad \mathrm{amp}-\mathrm{m}^{2}
$$

and (40) yields

$$
\mathrm{B}_{\theta}(\mathrm{r}, \theta, \mathrm{t})_{\max } \simeq-\frac{0.24}{\mathrm{r}^{3}} \mathrm{~W}(\mathrm{kTon}) \frac{\mathrm{Web}}{\mathrm{m}^{2}} \quad\left(\simeq-\left(\mathrm{B}_{\mathrm{z}}\right)_{\max }\right)
$$

At $1 \mathrm{~km}$ we would expect a peak $\left(\mathrm{B}_{\theta}\right)$-field of

$$
\begin{aligned}
\|\left(\mathrm{B}_{\theta}\right)_{\max } \mid \text { at } \mathrm{r}=1 \mathrm{~km} & \simeq 0.24 \times 10^{-9} \mathrm{~W}(\mathrm{kTon}) \mathrm{web} / \mathrm{m}^{2} \\
& \simeq 0.24 \mathrm{~W}(\mathrm{kTon}) \mathrm{nT}
\end{aligned}
$$

For $\mathrm{r}=5 \mathrm{~km}, \sigma=0.001, \mathrm{t}_{\mathrm{r}} \simeq 25 \times 0.3=7.5 \mathrm{~ms}<30 \mathrm{~ms}$ and

$$
\begin{aligned}
\left(\mathrm{B}_{\theta}\right)_{\max } \text { at } \mathrm{r}=5 \mathrm{~km} & \simeq 0.24\left(\frac{1}{5}\right)^{3} \mathrm{~W}(\mathrm{kTon}) \quad \mathrm{nT} \\
& \simeq 1.9 \mathrm{~W} \text { (kTon) } \mathrm{pT}
\end{aligned}
$$

However if $\mathrm{r}=5 \mathrm{~km}, \sigma=10^{-2}, \mathrm{t}_{\mathrm{r}}=78 \mathrm{~ms}>30 \mathrm{~ms}$ and we would have to evaluate (37) more carefully. 
Now we assume a "worst case" of $\mathrm{r}=5 \mathrm{~km}, \sigma=.04 \mathrm{mho} / \mathrm{m} . \mathrm{t}_{\mathrm{r}}=310 \mathrm{~ms}>$ Bubble duration of $50 \mathrm{~ms}$ according to Wouter's [6, Fig 4.3; the $\mathrm{m}(\mathrm{t})$-shape is a half-sinusoid, shortened on the decreasing side]. The Green-function $h_{\theta}(T)$ is shown in Miller's Fig. 3 [6]. Now we must evaluate the integral in (37) more carefully in order to estimate $\dot{\mathrm{H}}_{\theta}(r, \theta, t)_{\max }$. First we take

$\frac{\partial}{\partial t} \int_{0}^{t}-$. There is no contribution from differentiating the limit because $m_{z}(0)=0$.

Differentiation of $m_{z}\left(t-t^{\prime}\right)$ in the integrand yields a $\cos \left(60 t_{\text {sec }}\right)$-behavior - see below. From the plot of $h_{\theta}\left(T=t / t_{\zeta}\right)$ we approximate it by a sinusoid. From (35),

$$
\left(1-\frac{\mathrm{r}^{2} \mu_{\mathrm{o}} \sigma}{4 \mathrm{t}^{\prime}}\right) \frac{\exp \left(-\mathrm{r}^{2} \mu_{\mathrm{o}} \sigma / 4 \mathrm{t}^{\prime}\right)}{\left(4 \mathrm{t}^{\prime} / \mu_{\mathrm{o}} \sigma\right)^{5 / 2}} \simeq \frac{1}{\mathrm{r}^{5}} \mathrm{~h}_{\theta}\left(\mathrm{T}^{\prime}=\mathrm{t}^{\prime} / \mathrm{t}\right) \simeq \frac{1}{\mathrm{r}^{5}} 1.75 \sin \left[\pi \frac{\mathrm{T}^{\prime}-0.1}{.32}\right]
$$

over $0.1 \leq \mathrm{T}^{\prime} \leq 0.42$. We approximate the $\mathrm{m}_{\mathrm{z}}(\mathrm{t})$ Bubble history by a sinusoid, as Wouters did [ 5 , Fig. 4.3],

$$
m_{z}(t)=\left(m_{z}\right)_{\max } \sin \left(\pi \frac{t(m s)}{52.4}\right)
$$

so $\dot{m}_{\mathrm{z}}(t)=60\left(\mathrm{~m}_{\mathrm{z}}\right)_{\max } \cos \left(60 \mathrm{t}_{\mathrm{sec}}\right)$ over $0 \leq \mathrm{t} \leq 52.4 \mathrm{~ms}$. Then, using (41), we write (37) with $\sin \theta \simeq 1$ as

$$
\dot{\mathrm{B}}_{\theta}(\mathrm{r}, \theta, \mathrm{t})_{\text {net }}=-\frac{4(60)(1.75)}{\pi \sqrt{\pi} \sigma} \frac{\left(\mathrm{m}_{2}\right)_{\max }}{\mathrm{r}^{5}} \int_{, 031}^{\mathrm{t} s .25 \mathrm{t}_{\mathrm{r}}=.077} \cos \left[60\left(\mathrm{t}-\mathrm{t}^{\prime}\right)\right] \sin \left[\pi \frac{\mathrm{t}^{\prime}-.1 \mathrm{t}_{\mathrm{r}}}{.32 \mathrm{t}_{\mathrm{r}}}\right] d \mathrm{t}^{\prime}
$$

in which $\sigma=.04, \mathrm{r}=5 \times 10^{3} \mathrm{~m}$. There is an additional constant of $\mathrm{t}-\mathrm{t}^{\prime}<.05 \mathrm{sec}$, the Bubble duration.

The integral of (47) maximizes at $t \simeq .25 \mathrm{t}_{\mathrm{r}}$ and has the value $\simeq 1.87 \times 10^{-2}$. This makes 
$\dot{\mathrm{B}}_{\mathrm{o}}\left(\mathrm{r}=5 \mathrm{~km}, \theta=90^{\circ}, \mathrm{t}\right)_{\max }=1.7 \times 10^{-11} \mathrm{~W}(\mathrm{kTon}) \frac{\mathrm{T}}{\mathrm{sec}}$

From an estimate analgous to (47) we would expect a peak $B_{\theta}$-field of about

$\left(\mathrm{B}_{\theta}\right)_{\max }, \mathrm{r}=5 \mathrm{~km}, \sigma=.04, \simeq 0.5 \mathrm{~W}(\mathrm{kTon}) \quad \rho \mathrm{T}$,

due to $\mathrm{m}_{\mathrm{z}}$, neglecting reflection from the earth-air interface. $\mathrm{m}_{\mathrm{x}}$ would not contribute to this EMF directly near the interface but it induces an $\mathrm{m}_{\mathrm{z}}$ which would contribute, albeit a small amount (see later discussion).

Eq. (49) represents a measurable EMF for $W \geq 10$ kTon for this "worst case"!

The direct, infinite-medium fields due to the $\mathrm{m}_{\mathrm{x}}$-component of the Bubble can often be estimated using the Green-functions (34)-(36) but for a source rotated from alignment with the Zaxis (origin at the fireball) to alignment with the $\mathrm{X}$-axis. The coordinate transformations to the $h_{x, y, z}-$ and $e_{x, y, z}$-fields are readily performed.

\subsection{The Fields Including the Earth-Air Interface}

Miller [6] has expressed the $\Pi_{\mathbf{x}}$ - and $\Pi_{\mathbf{z}}$-functions, from which the fields are obtained by differentiation, as double integrals over frequency $\omega$ and cylindrical radial propagation constant, $\alpha$. The $m_{z}$-fields are given by three $\Pi_{z}$-functions, $\Pi_{z o}$ for the source-driven field incident on the interface, $\Pi_{\mathrm{zx}}$ for the field reflected from the interface at $\mathrm{z}=\mathrm{h}$, and $\Pi_{\mathrm{zt}}$ for the transmitted field. These are formally, in cylindrical coordinates,

$$
\Pi_{z o}(\rho, z, t)=\frac{i m_{z o}}{2 \pi} \int_{-\infty}^{\infty} d \omega e^{-i \omega x} \int_{0}^{\infty} \alpha d \alpha J_{0}(\alpha \rho) \frac{e^{i} \gamma z}{\gamma}, \quad z>0
$$

Here $\gamma=\sqrt{i \omega / q c-\alpha^{2}}$ CGS, $i=\sqrt{-1}$, and $q$ is defined in (24). 


$$
\Pi_{z}(\rho, z, t)=-\frac{i_{z o}}{2 \pi} \int_{-}^{+} d \omega e^{-i \omega t} \int_{0}^{\infty} d \alpha \frac{\alpha}{\gamma} \frac{\beta-\gamma}{\beta+\gamma} J_{0}(\alpha \rho) e^{-i \gamma z} e^{i 2 \gamma h}, \quad z \leq h
$$

and

$$
\Pi_{z t}(\rho, z, t)=\frac{i m_{z o}}{2 \pi} \int_{-}^{+} d \omega e^{-i \omega t} \int_{0}^{\infty} d \alpha \frac{2 \alpha}{\beta+\gamma} J_{o}(\alpha \rho) e^{i \beta z} e^{i(\gamma \beta) h}, \quad z \geq h
$$

where $\beta=\sqrt{(\omega / c)^{2}-\alpha^{2}}$.

Despite Miller's arguments that $|\beta|<<\mid$ for all $\omega$ except in a narrow range such that $\mid \omega / \mathrm{q} d \simeq \simeq \alpha^{2}-$ which implies that on the surface $\mathrm{z}=\mathrm{h}$

$$
\mathrm{E}_{\mathrm{x}, \mathrm{y}}^{\text {net }} \simeq 2 \mathrm{E}_{\mathrm{x}, \mathrm{y}}^{\mathrm{inc}}, \mathrm{E}_{\mathrm{z}}^{\text {net }} \equiv 0,\left|\mathrm{H}_{\mathrm{x}, \mathrm{y}}^{\text {net }}\right|<<\left|\mathrm{H}_{\mathrm{x}, \mathrm{y}}^{\mathrm{inc}}\right|, \mathrm{H}_{\mathrm{z}}^{\text {net }} \simeq 2 \mathrm{H}_{\mathrm{z}}^{\text {inc }}
$$

it will be "safer" to evaluate the double integrals for $\Pi_{\mathrm{zr}}$ and $\Pi_{\mathrm{zt}}$ over the significant narrow ranges of $\omega$ and $\alpha$ and then evaluate the $r-$ and $t$-fields near the interface, using $\Pi_{\mathbb{Z}}$ and $\Pi_{z t}$, respectively and the above, from

$$
\begin{aligned}
& E_{x}\left(m_{z}\right)=-\frac{1}{c} \frac{\partial}{\partial t} \frac{\partial \Pi_{z}}{\partial y}, E_{y}\left(m_{z}\right)=+\frac{1}{c} \frac{\partial}{\partial t} \frac{\partial \Pi_{z}}{\partial x}, E_{z} \equiv 0 \\
& H_{x}\left(m_{z}\right)=\frac{\partial}{\partial x} \frac{\partial \Pi_{z}}{\partial z}, H_{y}=\frac{\partial}{\partial y} \frac{\partial \Pi_{z}}{\partial z}, H_{z}=-\left(\frac{\partial^{2}}{\partial x^{2}}+\frac{\partial^{2}}{\partial y^{2}}\right) \Pi_{z} .
\end{aligned}
$$


Of more interest are the $m_{x}$-fields. (At NTS, $m_{z}=m \cos 30^{\circ}$ ) $m_{x}=+m \sin 30^{\circ}$ ). Miller distinguishes two cases: (i) $\left|\alpha^{2}\right|<<\mid \omega / \mathrm{qd}$ and (ii) $\alpha^{2} \geq|\omega / / \mathrm{q}|$. Let us conservatively examine his criteria. First, let $\mathrm{h} \geq 100 \mathrm{~m}$ (depth of burial); $\sigma \geq 9 \times 10^{6} \mathrm{esu}=10^{-3} \mathrm{mho} / \mathrm{m}$; then

$$
\left(\frac{h}{q}\right)_{\min }=\frac{4 \pi}{c}(h \sigma)_{\min } \simeq 40 .(\text { CGS })
$$

Let $\operatorname{Im}(\gamma) \cdot h \leq 5$, the range where the incident fields are significant on the interface. Then

$\sqrt{\frac{\omega}{\mathrm{qc} 2}} \mathrm{~h}=\frac{\mathrm{h}}{\mathrm{q} \sqrt{2}} \sqrt{\frac{\omega \mathrm{q}}{\mathrm{c}}} \leq 5$ and

$$
\sqrt{\frac{\omega \mathrm{q}}{\mathrm{c}}} \leq \frac{5 \sqrt{2}}{(\mathrm{~h} / \mathrm{q})_{\min }} \simeq 0.18, \quad \frac{\omega \mathrm{q}}{\mathrm{c}} \leq .032
$$

For case (i) $|\beta| \geq \frac{\omega}{c}$ (except for a narrow range $|\alpha|$ about $\left|\frac{\omega}{c}\right|$ ) and

$$
|\mathrm{q} \gamma=| \sqrt{\frac{\omega \mathrm{q}}{c}}|,| \frac{\omega}{\mathrm{c}} \mathrm{q} \gamma \mid \simeq \frac{\omega}{\mathrm{c}} \sqrt{\frac{\omega \mathrm{q}}{\gamma}} \text { and }
$$

(i) $\left|\frac{\omega}{c} q \gamma\right| \ll \beta$ as $\sqrt{\frac{\omega q}{c}} \leq 0.18 \ll 1$ (somewhat marginal).

For case (ii) $\alpha^{2}>>\left(\frac{\omega}{c}\right)^{2}$ and $|\beta| \simeq|\alpha|$ and $|y| \leq|\alpha|$

so

(ii)

$$
|\beta| \gg|| \frac{\omega \mathrm{q}}{\mathrm{c}} \gamma \mid \text { because }\left|\frac{\omega \mathrm{q}}{\mathrm{c}}\right| \leq .032
$$

For both these cases $\frac{\omega}{c} \mathrm{q} \eta|<| \beta \mid$ except in the narrow $\omega$-range 


$$
\begin{aligned}
& \quad|\beta| \simeq \sqrt{2 \frac{\omega}{c} \mid} \sqrt{\frac{\omega}{c}-\alpha \mid} \simeq\left|\frac{\omega}{c} q \gamma\right| \simeq\left|\frac{\omega}{c} \sqrt{\frac{i \omega q}{c}}\right| \leq 0.18 \frac{\omega}{c} \\
& \text { or } \\
& \text { or } \\
& 2 \mid \frac{\omega}{c}\left(\frac{\omega}{c}-\alpha \mid \leq\left(\frac{\omega}{c}\right)^{2}(.032)\right. \\
& \left|\frac{\omega}{c}-\alpha\right| \leq 0.016\left|\frac{\omega}{c}\right|
\end{aligned}
$$

Therefore we can assume in Miller's (34) [6] that

$$
\mathrm{a} \simeq-1, \mathrm{~b} \simeq 2 \gamma / \beta
$$

and that his (44), (45) are good approximations. $\Pi_{\mathbf{x t}}$ above ground is

$$
\Pi_{x t} \cong \frac{i_{x 0}}{\pi} \int_{-\infty}^{\infty} d \omega e^{-i \omega t} \int_{0}^{\infty} \alpha d \alpha J_{o}(\alpha \rho) \frac{e^{i \beta(z h)}}{\beta} e^{i \gamma h}, \quad z \geq h
$$

and $\Pi_{\mathrm{zt}}\left(\mathrm{m}_{\mathrm{x}}\right)$ induced by $\mathrm{m}_{\mathrm{x}}$ is

$$
\Pi_{z t}\left(m_{x}\right)=-\frac{\partial}{\partial x} \frac{m_{x 0}}{\pi} \int_{-}^{+} d \omega e^{-i \omega t} \int_{0}^{\infty} \alpha d \alpha J_{0}(\alpha \rho) \frac{e^{i \beta(z h)}}{\beta(\beta+\gamma)} e^{i \gamma h}, \quad z \geq h
$$

With $\prod_{x t}$ of (64) the transmitted Green-function $e_{\mathbf{z}}$-field just above ground at $z \geq h$ due to $\mathrm{m}_{\mathrm{x}}$ is

$$
e_{\text {dt }}\left(m_{x}\right)=-\frac{16 m_{x} q c}{\sqrt{\pi} r^{\prime} h^{4}}\left(8 \frac{q^{2}}{h^{2}}\right) \sin \theta \sin \phi\left(\frac{t_{h}}{r^{\prime} / c} \frac{\partial}{\partial T}+\frac{\partial^{2}}{\partial T^{2}}\right) U(T)
$$




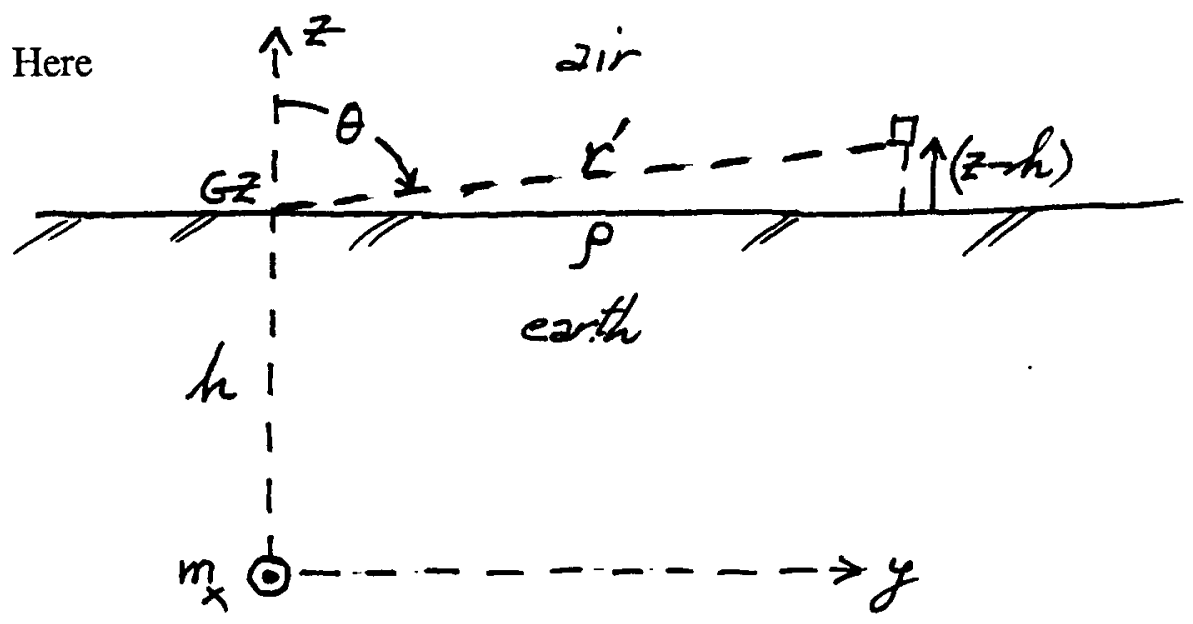

$$
\begin{aligned}
& \mathrm{r}^{\prime}=\sqrt{(\mathrm{z}-\mathrm{h})^{2}+\rho^{2}} \quad \sin \phi=\mathrm{y} / \rho, \cos \phi=\mathrm{x} / \rho \\
& \mathrm{T}=\tau / \mathrm{t}_{\mathrm{h}}, \mathrm{t}_{\mathrm{h}}=\mathrm{h}^{2} / 4 \mathrm{qc}, \quad \tau=\mathrm{t}-\mathrm{r}^{\prime} / \mathrm{c} \\
& \mathrm{U}(\mathrm{T})=\mathrm{T}^{-3 / 2} \mathrm{e}^{-1 / \mathrm{T}}
\end{aligned}
$$

Miller implies (at least to this writer) that just above the interface $E_{z}^{\text {net }}$ is finite, $H_{x, y}^{\text {net }} \rightarrow 0$ as $\mathrm{z} \rightarrow \mathrm{h}^{+},\left(\mathrm{E}_{\mathrm{x}} \equiv 0\right)$ and $\mathrm{E}_{\mathrm{y}}^{\text {net }}, \mathrm{H}_{\mathrm{z}}^{\text {net }}$ are twice their incident field values. He also says $\left|\Pi_{z t}\left(m_{x}\right)<<\right| \Pi_{x t} \mid$ for $r^{\prime}>h$, implying $\Pi_{z t}\left(m_{x}\right)$-generated fields are small.

However these assertions remain to be checked. The Green function $h_{x}\left(\Pi_{x t}\right)$-field evaluates, by Miller's procedure, to

$$
\begin{gathered}
h_{x}\left(\Pi_{x t}\right)=-\left(\frac{\partial^{2}}{\partial y^{2}}+\frac{\partial^{2}}{\partial z^{2}}\right) \Pi_{x t}=\frac{8 m_{x} q c}{\sqrt{\pi} h^{2} r^{\prime}}\left(\frac{4 q}{h^{2}}\right)^{2}\left\{\left(2-3 \sin ^{2} \theta \sin ^{2} \phi\right) .\right. \\
\left.\cdot\left[\left(\frac{h^{2}}{4 q}\right)^{2} \frac{1}{\left(r^{\prime}\right)^{2}} U(T)+\frac{h^{2}}{4 q} \frac{1}{r^{\prime}} \frac{\partial}{\partial T} U(T)\right]-\sin ^{2} \theta \sin ^{2} \phi \frac{\partial^{2}}{\partial T^{2}} U(T)\right\},
\end{gathered}
$$

where $\theta=90^{\circ}$ at $z=h^{+}$, and 


$$
\begin{gathered}
\mathrm{h}_{\mathrm{y}}\left(\Pi_{\mathrm{xt}}\right)=\frac{\partial^{2}}{\partial \mathrm{x} \partial \mathrm{y}} \Pi_{\mathrm{xt}}=\frac{8 \mathrm{~m}_{\mathrm{x}} \mathrm{qc}}{\sqrt{\pi} \mathrm{h}^{2}} \frac{1}{\mathrm{r}^{\prime}}\left(\frac{4 \mathrm{q}}{\mathrm{h}^{2}}\right)^{2}\left\{3\left(\frac{\mathrm{h}^{2}}{4 \mathrm{q}}\right)^{2} \frac{1}{\left(\mathrm{r}^{\prime}\right)^{2}} \mathrm{U}(\mathrm{T})+\right. \\
\left.+3 \frac{\mathrm{h}^{2}}{4 \mathrm{q}} \frac{1}{\mathrm{r}^{\prime}} \frac{\partial}{\partial \mathrm{T}} \mathrm{U}(\mathrm{T})+\frac{\partial^{2}}{\partial \mathrm{T}^{2}} \mathrm{U}(\mathrm{T})\right\} \sin ^{2} \theta \sin \phi \cos \phi \\
\mathrm{h}_{\mathrm{z}}\left(\Pi_{\mathrm{xt}}\right)=\frac{\partial^{2}}{\partial \mathrm{x} \partial \mathrm{z}} \Pi_{\mathrm{xt}}=0 \text { at } \mathrm{z}=\mathrm{h}^{+} \text {because } \frac{\partial \mathrm{r}^{\prime}}{\partial \mathrm{z}}=0 \text { there }
\end{gathered}
$$

It is certainly not obvious that these $h_{x, y}$-transmitted fields are $\simeq 0$ as Miller apparently claims. We must add to them the fields generated by $\Pi_{\mathfrak{z t}}\left(\mathrm{m}_{\mathrm{x}}\right)$ of $(65)$, and the relevant integrals probably should be evaluated numerically because of the non-trivial factor $(\beta+\gamma)$ in the denominator.

In conclusion, the temporal field components just above the earth's surface should be evaluated carefully by the above formulas when designing an experiment to measure yield of an underground explosion at distances of $1 \leq \rho \leq 5 \mathrm{~km}$.

\subsection{Spectra of the Fields}

For the spectra of the Green-functions "direct" or incident fields (25) - (27) or (34) - (36) due to $m_{z} \delta(t)$ and the $\prod_{x t}$-induced total fields of $(66),(68)-(70)$ we need the Fourier transform of $e^{-\gamma / t} t^{-5 / 2}, e^{-\gamma / t} t^{-7 / 2}, e^{-\gamma / t} t^{-9 / 2}$, where $\gamma=t_{r}$ or $t_{h}$. To evaluate

$$
F_{5 / 2}=\int_{0}^{\infty} t^{-5 / 2} e^{-\gamma / t} e^{-i \omega t} d t
$$

substitute $\mathrm{t}=1 / \mathrm{x}$ so it becomes 


$$
F_{5 / 2}=\int_{0}^{\infty} d x x^{1 / 2} e^{-\gamma x} e^{-i \omega / x}
$$

From the Tables of Integrals, Series and Products, I. S. Gradshteyn and I. M. Ryzhik, p 340, \#9

$$
\int_{0}^{\infty} x^{\nu-1} e^{-\gamma x} e^{-\beta / x} d x=2\left(\frac{\beta}{\gamma}\right)^{v / 2} K_{v}(2 \sqrt{\beta \gamma})\left\{\begin{array}{l}
\operatorname{Re} \beta>0 \\
\operatorname{Re} \gamma>0
\end{array}\right.
$$

Let $v=3 / 2, \beta=i \omega$ so

$$
\mathrm{F}_{5 / 2}=2\left(\frac{\mathrm{i} \omega}{\gamma}\right)^{3 / 4} \mathrm{~K}_{3 / 2}(2 \sqrt{\mathrm{i} \omega \gamma})
$$

Let $z=2 \sqrt{i \omega \gamma}$; from $p 967$ of the same reference

$$
K_{n+\frac{1}{2}}(z)=\sqrt{\frac{\pi}{2 z}} e^{-z} \sum_{k=0}^{n} \frac{(n+k) !}{k !(n-k) !(2 z)^{k}} .
$$

This gives

$$
\mathrm{F}_{5 / 2}=\sqrt{\pi}(i \omega)^{1 / 2} \frac{1}{\gamma} \mathrm{e}^{-2 \sqrt{i \omega \gamma}}\left[1+\frac{1}{z}\right]
$$

$F_{7 / 2}$ and $F_{9 / 2}$, obtained by replacing $t^{-5 / 2}$ by $t^{-7 / 2}$ or $t^{-9 / 2}$ in (71), are evaluated similarly.

With these the spectra of (34) - (36) in MKS units with $\gamma=t_{r}=r^{2} \mu_{0} \sigma / 4$ are

$$
\begin{gathered}
h_{r}(r, \theta, \omega)=\frac{1}{2 \pi} \frac{m_{z}}{r^{2}} \sqrt{1 \omega \mu_{o} \sigma} \mathrm{e}^{-2 \sqrt{i \omega \gamma}} \cos \theta\left[1+\frac{1}{2 \sqrt{i \omega \gamma}}\right] \\
\stackrel{\omega \rightarrow 0}{\longrightarrow} \frac{m_{z}}{2 \pi r^{3}} \cos \theta
\end{gathered}
$$




$$
\begin{gathered}
h_{\theta}(r, \theta, \omega)=\frac{1}{4 \pi \mathrm{r}} i \omega \mu_{0} \sigma \mathrm{e}^{-2 \sqrt{i \omega \gamma}} \sin \theta\left[1+\frac{3}{2 \sqrt{i \omega \gamma}}+\frac{3}{4 i \omega \gamma}\right] \\
\stackrel{\omega \rightarrow 0}{\longrightarrow} \frac{\mathrm{m}_{\mathrm{z}}}{4 \pi \mathrm{r}^{3}} \sin \theta
\end{gathered}
$$

and

$$
\begin{array}{rl}
e_{\theta}(r, \theta, \omega)= & \frac{5 m_{z}}{4 \pi} \frac{i \omega \mu_{o}}{r^{2}} e^{-2 \sqrt{i \omega \gamma}}\left[\left(1+\frac{3}{2 \sqrt{i \omega \gamma}}+\frac{3}{4 i \omega \gamma}\right)+\right. \\
& \left.\frac{2}{5} \sqrt{i \omega \gamma}\left(1+\frac{3}{\sqrt{i \omega \gamma}}+\frac{15}{4 i \omega \gamma}+\frac{15}{8(i \omega \gamma)^{3 / 2}}\right)\right] \\
\underline{\omega \rightarrow 0} & 0 .
\end{array}
$$

The limiting values of (77) - (79) as $\omega \rightarrow 0$ are the well-known expressions for the MKS fields of a static magnetic dipole. These results check the transformation formulas for conversion of the CGS (25) - (27) of Miller to MKS forms (34) - (36).

The spectrum of an event field like (38) is the product of the spectra of the Green-function and magnetic dipole.

\section{A Summary of Zablocki's Report [7]}

In his summary he states that the electric field components recorded from eleven underground events at NTS are only a few microvolts $/ \mathrm{m}$ at distances $<10 \mathrm{~km}$ from the shot point, and that they decay approximately as $\mathrm{r}^{3}$. The magnitudes are proportional to $\mathrm{W}(\mathrm{kTon})^{1 / 4}$. However Miller [6] gives an $\mathrm{r}^{-6}$ dependence for $\cdot \mathrm{E}_{\phi}$ and implies magnitudes proportional to $\mathrm{W}$.

Zablocki assumes final cavity radius $r_{c}$ varies as $17 \mathrm{~W}^{1 / 3}$ but takes magnetic dipole $\mathrm{m} \simeq \mathrm{H}_{\mathrm{o}} \mathrm{r}_{\mathrm{c}}^{3}$ instead of $2 \pi \mathrm{H}_{\mathrm{o}} \mathrm{r}_{\mathrm{c}}^{3}\left(\mathrm{H}_{\mathrm{o}}=\right.$ earth field). Thus he obtains $\mathrm{m}_{\max }=2.5 \times 10^{5} \mathrm{~W}$ instead of $1.48 \times 10^{6} \mathrm{~W}$ in our (41). 
The theory in Zablocki's report is based on J. R. Wait's work [8] for a single-frequency magnetic dipole at the earth's surface. This predicts magnetic field $H_{r} \sim r^{-4}$ in [7, (9)] and $E_{\phi} \sim r^{4}$ in $[7,(11)]$, whereas Miller's space-time analysis shows $\mathrm{H}_{\mathrm{r}}, \mathrm{H}_{\theta} \sim \mathrm{r}^{-5}$ and $\mathrm{E}_{\phi} \sim \mathrm{r}^{-6}$. Because the theory is single-frequency the dipole is not at the event point, and the fields differ qualitatively from Miller's, I regard all of Zablocki's analysis as suspect.

Now we will summarize the characteristics of several explosions discussed by Zablocki and make field amplitude estimates using Miller's MKS formulas.

5.1 Nougat Test Series (1961 - 1963). Peak amplitudes accurately recorded.

1. Fisher. $\mathrm{r} \simeq 4 \mathrm{~km}$ from fireball to instruments, Alluvium of $\sigma=0.02 \mathrm{mho} / \mathrm{m}$. $\mathrm{t}_{\mathrm{r}}=$ $\mathrm{r}^{2} \mu_{\mathrm{o}} \sigma / 4=100 \mathrm{~ms}$. Spectral analysis of the Green-function fields shows $\mathrm{f}_{\max } \approx \frac{6}{2 \pi \mathrm{t}_{\mathrm{T}}}=9 \mathrm{~Hz}$, much smaller than the spectral width of the Bubble, $\leq 200 \mathrm{~Hz}$.

We need a formula for $E_{\phi}(r, \theta, t)_{\text {net }}$ analogous to (37). From (33) and (36) it is

$$
E_{\phi}(r, \theta, t)=\frac{20}{\pi \sqrt{\pi} \mu_{0} \sigma^{2}} \frac{1}{r^{6}} \sin \theta \int_{0}^{t} m_{z}\left(t-t^{\prime}\right)\left(1-\frac{2}{5} \frac{t^{\prime}}{t^{\prime}}\right) \frac{e^{-t_{r} / t^{\prime}}}{\left(t_{L} / t^{\prime}\right)^{7 / 2}} d t^{\prime}
$$

We estimate $\left(\int_{0}^{\mathrm{t}} \mathrm{dt^{ \prime }}-\right)_{\max } \simeq\left(\mathrm{m}_{\mathrm{z}}\right)_{\max } 2 \int_{0}^{.05} \sin ^{2}\left(\pi \frac{\mathrm{t}^{\prime}}{.05}\right) d \mathrm{t}^{\prime} \cong .05\left(\mathrm{~m}_{\mathrm{z}}\right)_{\max }$ and this gives

$$
\mathrm{E}_{\phi}\left(\mathrm{r}, 90^{\circ}, \mathrm{t}\right)_{\max } \simeq 1.7 \times 10^{-6} \mathrm{~V} / \mathrm{m}
$$


which is ten times higher than Zablocki's value [7, Table 2]. Perhaps $\sigma$ was closer to .04 than .02 .

Another measurement at $\mathrm{r}=6.5 \mathrm{~km}$ yielded $.06 \mu \mathrm{V} / \mathrm{m}$, whereas we estimate, from Zablocki's value for $E_{\phi}, 0.17(4 / 6.5)^{6} \simeq .009 \mu \mathrm{V} / \mathrm{m}$, too low. So we don't estimate the Fisher $\mathrm{E}_{\phi}$-fields very well with (80).

2. Hardhat. The peak $\left|E_{\phi}\right|$ was $>100 \mu \mathrm{V} / \mathrm{m}$, saturated. $t_{\mathrm{r}} \simeq .16 \mathrm{msec}$, very small, according to $\mathrm{r}=.61 \mathrm{~km}, \sigma=0.00135$ for this event.

3. Aardvark. $W=37 \mathrm{kTon}, \mathrm{r}=3.4 \mathrm{~km}$, in Alluvium of $\sigma=.02$. $\left(\mathrm{E}_{\phi}\right)_{\text {peak }}$ measured was $12 \mu \mathrm{V} / \mathrm{m}$. $\mathrm{t}_{\mathrm{r}}=72 \mathrm{~ms}$, comparable to $100 \mathrm{~ms}$ for Fisher. So we estimate from Fisher

$$
\left(\mathrm{E}_{\phi}\right)_{\max } \simeq 1.7 \times 10^{-6}\left(\frac{4}{3.4}\right)^{6}\left(\frac{37}{13.5}\right) \simeq 12.3 \mu \mathrm{V} / \mathrm{m}
$$

coincidentally very close!

\subsection{Hardtack, phase II (1958) [7, Fig. 10]}

The peak E-fields measured $1-2 \mu \mathrm{V} / \mathrm{m}$, with $\mathrm{E}_{\phi}$ predominant, suggesting a magnetic dipole source. $\sigma$-value is not quoted. The $5 \mathrm{kTon}$-curve of $\mathrm{E}_{\phi}$ looks most like it was generated by a magnetic dipole; the 19 kTon-peak should be four times higher but measures only two times higher than the $5 \mathrm{kTon}$-peak. The $\mathrm{E}_{\phi}$-curve for $19 \mathrm{kTon}$ is very ragged.

Estimating $\sigma=0.01$, for $\mathrm{r}=6.72 \mathrm{~km}, \mathrm{t}_{\mathrm{r}}=140 \mathrm{~ms} . \omega \geq \frac{2}{2 \pi \mathrm{t}_{\mathrm{T}}}$ so $\mathrm{f} \geq 2-3 \mathrm{~Hz}$; the $2-8 \mathrm{~Hz}$ spectral peaks could be due to a magnetic dipole.

There is a strong $\mathrm{E}_{\mathrm{T}}$-component for event $\mathrm{V}$, perhaps due to an electric dipole source. 


\subsection{Gnome (1961)}

Here $\mathrm{W}=3.1 \mathrm{kTon}, \mathrm{r}=7.75 \mathrm{~km}, \mathrm{f}<100 \mathrm{~Hz}$. There was halite $\left(\sigma \simeq 10^{-4}\right)$ around the cavity but did not typify the ground along the direct transmission path. We estimate $\sigma=0.01$, then $\mathrm{t}_{\mathrm{r}}=180 \mathrm{~ms}$. From Fisher, we expect

$$
\left(\mathrm{E}_{\phi}\right)_{\text {peak }} \simeq 1.7 \times 10^{-6}\left(\frac{4}{7.75}\right)^{6}\left(\frac{3.1}{13}\right) 2^{2}=0.03 \mu \mathrm{V} / \mathrm{m},
$$

whereas the measured value was $.21 \mu \mathrm{V} / \mathrm{m}$. Since $\left(\mathrm{E}_{\phi}\right)_{\text {peak }} \sim \sigma^{-2}$ it seems $\sigma$ is effectively

$\sqrt{\frac{3}{21}} \times 10^{-2} \simeq .38 \times 10^{-2} \mathrm{mho} / \mathrm{m}$. This would reduce $\mathrm{t}_{\mathrm{r}}$ to $180 \sqrt{\frac{1}{7}}=68 \mathrm{~ms}$ and increase the integral in (80). So perhaps $\sigma \simeq .60 \times 10^{-2}$.

\subsection{Bilby.}

$$
\mathrm{W}=200 \mathrm{kTon}, \mathrm{r}=7.62 \mathrm{~km}, \sigma=0.01 \text { (estimate), }\left(\mathrm{E}_{\phi}\right)_{\text {peak }} \text { measured }=3.6 \mu \mathrm{V} / \mathrm{m} . \mathrm{t}_{\mathrm{r}}=
$$
$180 \mathrm{~ms}$, and from Fisher

$$
\left(\mathrm{E}_{\phi}\right)_{\max } \geq 1.710^{-6}\left(\frac{4}{7.62}\right)^{6} \frac{200}{13.5} 2^{2}=2.1 \mu \mathrm{V} / \mathrm{m}
$$

rather close to the measured value.

We now summarize Zablocki's discussion. His Fig. 15 shows field relaxation time $\tau_{R}$ as yield-dependent, $\tau_{R}=30 \mathrm{~W}^{1 / 3} \mathrm{msec}$, from 5 nuclear events in the range $5<\mathrm{W}<200 \mathrm{kTon}$. But this functional form could be due to the variation of $t_{r}=r^{2} \mu_{0} \sigma / 4$, which changes the convolution integrals. Since his analysis is based on Wait's work at single frequency rather than on Miller's expressions many conclusions may be wrong.

For example, he concludes in [7, Fig. 3] for the Nougat series that radial $\mathrm{E}_{\mathrm{x}}$ is necessary to justify a magnetic dipole source. This is simply not so! 
Atop [7, p. 3541] he says the polarization is incompatible with a magnetic dipole for events I - IV and Hardhat. But this is probably due to the positive direction of $E_{\phi}$ in $\left[7\right.$, Fig. 1] and $H_{\phi}$ in [7, Fig. 4] — which are in the $-\mathrm{a}_{\phi}$ spherical coordinate direction! (Note the earth's $\mathrm{H}_{\mathrm{o}}$-field points downward at an angle of $30^{\circ}$ with the vertical at Las Vegas, so the magnetic dipole $\bar{m}(\mathrm{t})$ is upward at this angle. So $\mathrm{m}_{\mathrm{x}}>0$, with $\mathrm{x}$ in the geographic south direction.)

The curve-fit $\mid$ E| expression [7, (43)]

$$
\mathrm{E}=2.2 \times 10^{-2} \mathrm{~W}^{0.44} / \mathrm{r}_{\mathrm{km}}^{3} \quad \mu \mathrm{V} / \mathrm{m}
$$

was obtained from various events in which $\mathrm{E}_{\phi}$ was $\propto \mathrm{W}$ times the convolution integral in our (80), and the latter depends on $t_{r}$ in an involved way. So this formula for $|E|$ is deceptive.

Similarly, the curve-fit [7, Fig. 15] relating field relaxation time $\tau_{\mathrm{R}}$ to $\mathrm{W}$ is more subtle because of the involved dependence of the convolution integral on $t_{r}$ in (80). Note for $W=5$, Hardhat, $\tau_{R}=50 \mathrm{~ms}$, just the Bubble duration (according to Wouters) as expected for the small $\mathrm{t}_{\mathrm{r}}$ of $0.16 \mathrm{~ms}$. The dot to the left of Fig. 15 probably represents a small- $t_{\mathrm{r}}$ event too. If $\sigma=.02$ in Fisher, $\mathrm{E}_{\phi}(\mathrm{t})$ decreases rapidly for $\mathrm{t}>50 \mathrm{~ms}$ so we would expect $\tau_{\mathrm{R}}=50^{+} \mathrm{ms}$, as plotted. But if $\sigma$ $=.04, \mathrm{t}_{\mathrm{r}}=200 \mathrm{~ms}$, and $\tau_{\mathrm{R}}$ would be larger. And why weren't $\tau_{\mathrm{R}}$ of Fisher and Bilby $\left(\mathrm{t}_{\mathrm{r}}=\right.$ $180 \mathrm{~ms})$ comparable? Perhaps because the Fisher $t_{\mathrm{r}}$ was $\simeq 100 \mathrm{~ms}(\sigma \simeq .02)$, which would put Fisher closer to Aardvark ( $\mathrm{t}_{\mathrm{r}}=72 \mathrm{~ms}$ ) than to Bilby ....

At the very end of the article Zablocki acknowledges the dispersive nature of the fields in a conductive medium.

\section{Comments on the Report of Malik, Fitzhugh, and Homuth [3]}

These authors say in their abstract and conclusion that the late-time signals are probably explained by the seismoelectric effect proposed by Zablocki and Keller (1961 report). They say in 
their introduction [3]: "Despite over two decades of sporadic investigations the data are fragmentary and either incompletely or unconvincingly interpreted". The writer (RMB) heartily concurs.

Figures 2 and 3 of [3] show $E_{\mathrm{T}}(\mathrm{t})$ and $\mathrm{E}_{\phi}(\mathrm{t})$ are not due to a magnetic dipole because of their almost identical shapes!

Malik, et. al, recognize the diffusive nature of the fields but ignore the correct analysis of Miller [6] and instead refer to J. Wait's work, from which they quote an E-field space-time formula which disagrees with Miller's expression, our (36), and (80). Fig. 5 [3] for the radial electric field from a horizontal electric dipole at depth of $715 \mathrm{~m}$ shows we must include the field reflection and transmission from the earth interface. Space-time fields from a horizontal magnetic dipole, $\mathrm{m}_{\mathrm{x}}$, below the surface are quoted but they show only one Cartesian component, whereas Miller's (47), divided by (-i $\gamma)$ to give a $\Pi_{z}\left(m_{x}\right)$, and (32) with $a=-1$ for $\Pi_{x}\left(m_{x}\right)$ clearly show the presence of all $e_{x, y, z}$ away from the interface.

For the Lowball event $r=2.9 \mathrm{~km}$, the first pulse of $E_{\phi}$ with $55 \mu \mathrm{V} / \mathrm{m}$ maximum appears to come from magnetic dipole $m_{z}$. Figs. G-2 through G-9 refer to this event, and Malik, et. al., say the signals on the shorter time scale records ( $\leq 5 \mathrm{~ms}$ ) appear to be diffusive and due either to a magnetic Bubble as to an electroseismic effect. They note no azimuthal $E$ and so discount the Bubble. This contradicts the information in Appendix F containing the Lowball data - the "best data" of any of the events in [3] according to these authors. Fig. F-1 shows $\left(E_{\phi}\right)_{\max }=55 \mu V / m$ at $r=2.9 \mathrm{~km}$. There is a relevant static water level at $500 \mathrm{~m}$. With $\sigma=0.01$ (Table G-II) we have $t_{r}$ $=26 \mathrm{~ms}$.

We now estimate $\left(E_{\phi}\right)_{\max }$ with (80), in which $m_{z}(t) \simeq\left(m_{z}\right)_{\max } \sin [\pi \cdot t / 50 \mathrm{~ms}]$, and the integral is approximately 


$$
\int_{0}^{t} d t^{\prime}-\simeq \frac{0.8\left(m_{2}\right) \max }{r^{6}} \int_{0}^{t=t_{r}}\left(1-\frac{2}{5} \frac{t_{r}}{t^{\prime}}\right) \frac{e^{-t_{t} / t^{\prime}}}{\left(t^{\prime} / t_{\mathrm{r}}\right)^{7 / 2}} d t^{\prime}
$$

With $T^{\prime}=t^{\prime} / t_{\mathrm{r}}$ we have for $(86)$

$$
\int_{0}^{t_{\mathrm{T}}} d \mathrm{~T}^{\prime}-=-\frac{2}{5} \mathrm{t}_{\mathrm{T}}\left[\mathrm{T}^{-5 / 2} \mathrm{e}^{-1 / \mathrm{T}}\right]_{0}^{\mathrm{T}=1}
$$

Substitution of $(87),\left(\mathrm{m}_{\mathrm{z}}\right)_{\max }=1.48 \times 10^{6} \mathrm{~W}(\mathrm{KTon})$ and the other data into (80) gives

$$
\left(\mathrm{E}_{\phi}\right)_{\max } \simeq 0.22 \mathrm{~W}(\mathrm{kTon}) \mu \mathrm{V} / \mathrm{m}
$$

From $[3$, Table G-II] we estimate $\mathrm{W}=56 \mathrm{kTon}$, so

$$
\left(\mathrm{E}_{\phi}\right)_{\max } \simeq 12 . \mu \mathrm{V} / \mathrm{m} \text {, }
$$

fairly close to the measured $55 \mu \mathrm{V} / \mathrm{m}$.

\section{Review of J. Sweeney's Measurements [9]}

From FY1986 - 1988 he and his colleagues monitored ELF EM fields from underground events at NTS to determine whether they could be detected (yield estimation was not emphasized). Signals clearly related to underground tests were detected only when the sensors were $<10 \mathrm{~km}$ from surface ground zero. A major conclusion from the work was that ELF signals from underground tests of yields $<150$ kTon are generally lower than background signals caused by worldwide lightning activity and hence not detectable via resonances in the earth-ionospheric cavity. 
Below we compare measured peak fields with magnetic-dipole predictions for three tests discussed in [9] (The values of yields, W, are not quoted.). We assume $\sigma=0.01$ and neglect fields reflected and transmitted from the earth-air interface; i.e., we estimate the fields at the interface by their infinite-medium values.

\subsection{Hardin}

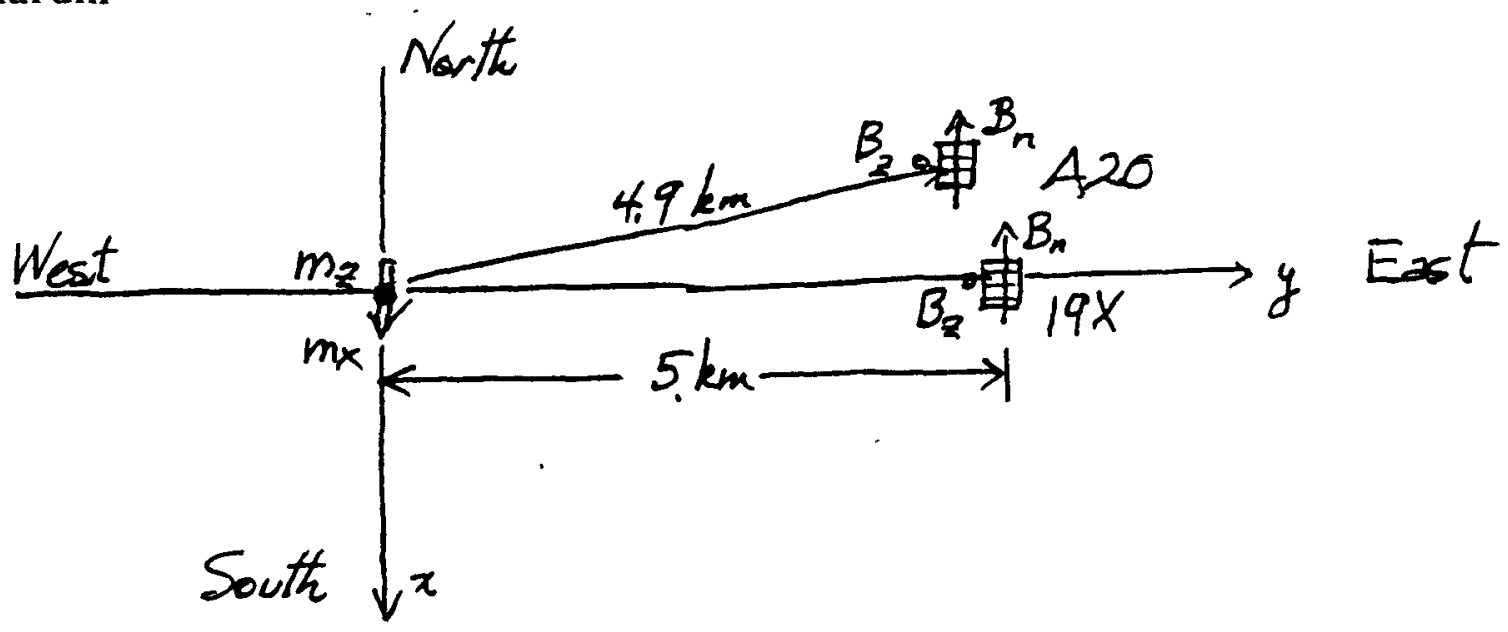

We note the shape of all the signals is double-polarity, not characteristic of the direct fields of a magnetic dipole. $\mathrm{H}_{\mathrm{n}}$ measured in the range (2.4-4.0) $10^{-5} \mathrm{~A} / \mathrm{m}[9$, Fig. 7] at both $\mathrm{A} 20$ and $19 \mathrm{X}$ sites, where $t_{r}=78 \mathrm{~ms}$. From (37), for $H_{\theta}$ of magnetic dipole $m_{x}$ at $\theta=90^{\circ}$ (in its coordinate system) we estimate

$$
\left(\mathrm{H}_{\theta}\right)_{\max } \simeq 0.61 \times 10^{-6} \mathrm{~W}(\mathrm{kTon})
$$

$\mathrm{H}_{\mathrm{z}}$ was $13 \mathrm{pT}$ at $\mathrm{A} 20$ and (26-38) pT at 19X measured [9, Fig. 9 and subsequent plots]. These translate to $1.04 \times 10^{-5} \mathrm{~A} / \mathrm{m}$ at A20 and $(2.1-3.0) 10^{-5} \mathrm{~A} / \mathrm{m}$ at $19 \mathrm{X}$. Our estimate is

$$
\left(\mathrm{H}_{\mathrm{z}}\right)_{\max } \simeq 1.05 \times 10^{-6} \mathrm{~W}(\mathrm{kTon}) \quad \mathrm{A} / \mathrm{m}
$$

at both sites, due to $m_{z}$. 
$E_{\phi}$ measured in the range $(3-30) \mu \mathrm{V} / \mathrm{m}$ [plots], due to $m_{\mathrm{z}}$. An estimate from (36), accounting carefully for the convolution integral, gives

$\left(\mathrm{E}_{\phi}\right)_{\max } \simeq .035 \mathrm{~W}(\mathrm{kTon}) \mu \mathrm{V} / \mathrm{m}$, at both $\mathrm{A} 20,19 \mathrm{X}$

$B_{e} \simeq B_{r}$ showed different character at $A 20$ than $19 X$, for unknown reasons.

\subsection{Kernville, site $H R$ at $8.8 \mathrm{~km}$}

$H_{r} \simeq H_{n}$ measured in the range $(2.0-2.4) 10^{-5} \mathrm{~A} / \mathrm{m}$ [9, Fig. 15 and subsequent plots]. However the double-polarity waveshape was not characteristic of the direct magnetic-dipole fields. The bandwidth of PDR-2 [9, Fig. 6(a)] was too limited; it should have been $\geq 50 \mathrm{~Hz}$. The $\mathrm{H}_{\mathrm{r}}$ estimate was

$$
\left(\mathrm{H}_{\mathrm{s}}\right)_{\max } \simeq 2.1 \times 10^{-8} \mathrm{~W}(\mathrm{kTon}) \quad \mathrm{A} / \mathrm{m},
$$

too low.

$\mathrm{B}_{\mathrm{z}}$ too, has the wrong waveshape. The measured $\mathrm{H}_{\mathrm{z}}$-peak [10, subsequent plots] is $21 \mathrm{pT}$ $=1.7 \times 10^{-5} \mathrm{~A} / \mathrm{m}$; the prediction due to $\mathrm{m}_{\mathrm{z}}$ is

$$
\left(\mathrm{H}_{\mathrm{z}}\right)_{\max } \approx 3.6 \times 10^{-8} \mathrm{~W} \quad \mathrm{~A} / \mathrm{m} \text {, }
$$

too low.

So the Kernville measurements are not predicted well by direct magnetic dipole fields; perhaps the inclusion of the effect of earth-air interface would improve matters.

\subsection{Belmont. [9, subsequent curves]}

(A) At site $\mathrm{EG}=6.2 \mathrm{~km}$ the measured $\left(\mathrm{H}_{\mathrm{z}}\right)_{\max }$ was $\simeq 9.6 \times 10^{-5} \mathrm{~A} / \mathrm{m}$. With $\mathrm{t}_{\mathrm{r}}=$ $120 \mathrm{~ms}$ the estimate from (80) and remark following is 


$$
\left(\mathrm{H}_{\mathrm{z}}\right)_{\max } \simeq \frac{3.6 \times 10^{-5}}{92} \mathrm{~W}=3.9 \times 10^{-7} \mathrm{~W} \mathrm{~A} / \mathrm{m}
$$

(B) At site A20 $=7.4 \mathrm{~km}$ the measured $\left(\mathrm{E}_{\phi}\right)=18 \mu \mathrm{V} / \mathrm{m}$. With $\mathrm{t}_{\mathrm{r}}=170 \mathrm{~ms}$ the estimate from (80) and remark subsequent is

$$
\left(\mathrm{E}_{\phi}\right)_{\max } \simeq 1.1 \times 10^{-8} \mathrm{~W} \quad \mathrm{~V} / \mathrm{m} \quad \text { (low) }
$$

The discrepancy is not due to $\mathrm{m}_{\mathrm{x}}$ or $\left(\mathrm{m}_{\mathrm{z}}\right)_{\text {electric dipole, }}$ and interface reflection would probably not account for much.

\section{Review of Classified Data for NTS Events}

Much data was inconsistent relative to a simple magnetic dipole source. Missing data in some cases prevented us from comparing theory and measurement. For the calculations made, direct-field estimates differed from measured values by factors in the $10-100$ range. The reasons for these discrepancies are not obvious.

\section{Conclusions}

We have compared measured early-time peak surface fields in various underground nuclear events with predictions from Miller's infinite-earth field expressions using Wouter's expression for the maximum magnetic dipole moment (with $\mathrm{W}^{3 / 4}$ changed to $\mathrm{W}$, yield) and its temporal history. Those comparisons sometimes differ within an order of magnitude of measurements reported by Zablocki, Sweeney, and Malik et. al., and sometimes by more, for reasons not fully understood. Miller's expressions allow us to correct for the earth-air interface, and the more accurate field formulas might agree better with measurements. Past instrumentation has sometimes lacked the required bandwidth, which can be estimated from the event-dipole time history and the spectra of Miller's Green-function fields. 


\section{Recommendations for Subsequent Work}

For an advanced concept project we propose field experiments, coupled with modeling, to (a) confirm the diffusion theory, (b) optimize and calibrate the measurement systems, and (c) understand better the nature of the EM source fields of an underground event. As an initial study to achieve goals (a) and (b) we propose to carry out a series of experiments at NTS with a downhole controlled source to simulate the magnetic-dipole source of an underground explosion. We will measure the fields produced with surface sensors. Depending on the design criteria, we might also be able to create a downhole or surface-horizontal electric dipole source and study its fields with suitably modified diffusive-field theory. This will allow us to develop ways to decomple better the effects of multiple sources.

The diffusion theory will be used to design the experiment and resolve such details as the necessary distances and orientation of the sensors and required bandpass of the measurement system. We will locate the magnetic dipole source at a depth of a few tens of meters in a borehole which has been logged so that the medium characteristics are well known. In this way we can see if the measurements made in the NTS EM environment confirm the theoretical predictions.

Once we have completed the initial calibration and field testing of the EM measurement system, we will be ready to field the system during underground tests. Sensors will be deployed at distances less than $5 \mathrm{~km}$ from GZ, and will be designed to decouple optimally the fields created by magnetic or electric dipoles. The data will then be used to predict yield from EM measurements. Based on the results of one or two tests, provided that the data collection is successful, we will be in a position to recommend whether the technique is successful enough to warrant further study as an alternative system for yield measurement. 


\section{Personnel and Funding Requirements}

Personnel needed to carry out this work are estimated to be: project manager, 0.1 FTE, EM field theory person, $0.25 \mathrm{FTE}$, field engineer, 0.25 FTE, field technician, 0.25 FTE, support from test designer to help us understand source characteristics, 0.15 FTE (optional). We will probably be able to design the measurement system using equipment available from previous ELF investigations and elements of the CSMS seismic system, but some additional funds will be needed for equipment. Additional funds will be needed for travel expenses for the field work. In summary, assuming 1 FTE total personnel expense and about $\$ 50 \mathrm{~K}$ for additional expenses, it will take about $\$ 150 \mathrm{~K}-\$ 200 \mathrm{~K}$ to carry out the project as outlined above. 


\section{References}

[1] P. J. Ebert, "Non-intrusive Verification", UCRL-101542 Preprint, paper for DOE Conference on Technology R\&D for Arms Control Verification, Los Alamos, Aug. 29-31, 1989. Preprint dated July 17, 1989.

[2] Y. P. Raizer, "The Deceleration and Energy Conversion of a Plasma Expanding in a Vacuum in the presence of a Magnetic Field", Zh. Priklad. Mek i Tek. Fiz; 619 (1963).

[3] Malik, Fitzhugh, and Homuth, "Electromagnetic Signals from Underground Nuclear Explosions", LA-10545 MS UC-34, Oct., 1985.

[4] W. C. Moss, "A Method to Estimate the Yield of an Underground Nuclear Explosion," J. App. Phys., 63, p 4771, (1988).

[5] L. F. Wouters, "The Underground Electromagnetic Pulse: Four Representative Models", Sec. 4, UCID-21720, June, 1989.

[6] L. W. Miller, "The Electromagnetic Pulse from an Underground Nuclear Explosion", LA5056, UC-34 Los Alamos Scientific Laboratory, Jan. 1973.

[7] C. J. Zablocki, "Electrical Transients Observed During Underground Nuclear Explosions", Jour. Geoph. Res., 71, pp 3523 - 3542, July 15, 1966.

[8] J. R. Wait, "Mutual Electromagnetic Coupling of Loops Over a Homogeneous Ground", Geophysics, 20 (3), pp 630-637, 1955.

[9] J. J. Sweeney, "An Investigation of the Usefulness of Extremely Low-Frequency Electromagnetic Measurements for Treaty Verification", UCRL-53899, Jan. 1989. 
DO Mot Mrrorllm

COVER

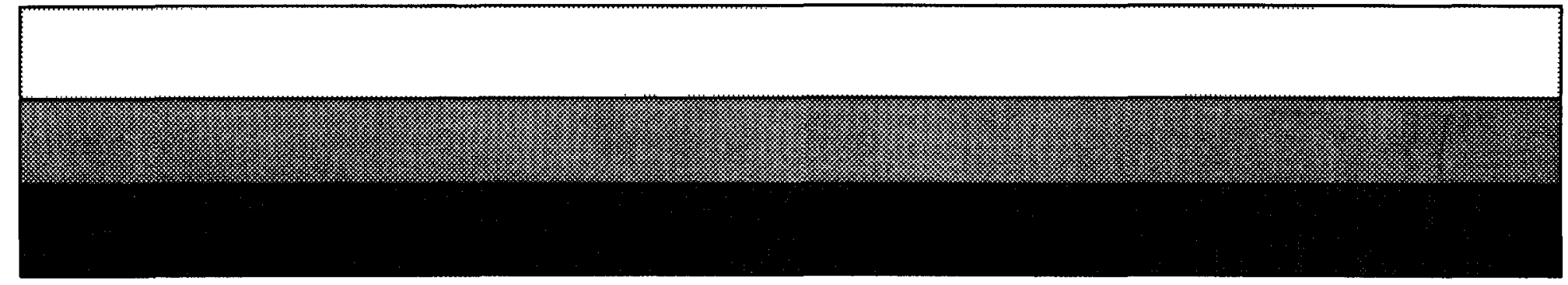

